\title{
AVALIAÇÃO DO EFEITO DA ACUPUNTURA E TÉCNICAS AFINS E PERFIL CLÍNICO E EPIDEMIOLÓGICO DE CÃES COM DOENÇAS NEUROLÓGICAS E OSTEOMUSCULARES ATENDIDOS EM SERVIÇO DE REABILITAÇÃO VETERINÁRIA
}

\section{RETROSPECTIVE STUDY OF DOGS WITH NEUROLOGIC AND MUSCULOSKELETAL DISEASES ATTENDED AT A REHABILITATION AND CHRONIC PAIN CONTROL SERVICE}

\author{
Nuno Emanuel Oliveira Figueiredo ${ }^{*}$ \\ Stelio Pacca Loureiro Luna ${ }^{1}$ \\ Jean Guilherme Fernandes Joaquim² \\ Heloisa Dellacqua Coutinho ${ }^{1}$ \\ 1Faculdade de Medicina Veterinária e Zootecnia - UNESP, Botucatu, SP, Brasil.
${ }^{2}$ Instituto Bioethicus, Botucatu, SP, Brasil.
*Autor para correspondência - emmanunno@gmail.com
}

\section{Resumo}

Este estudo retrospectivo avaliou 181 cães com doenças neurológicas e osteomusculares atendidos em um serviço de reabilitação e dor crônica, durante o período de 2013 a 2015. Objetivou-se caracterizar o perfil epidemiológico e clínico dos animais e analisar a eficácia da acupuntura (AP) e terapias afins e respectiva evolução clínica. O diagnóstico baseou-se no exame físico, neurológico, ortopédico e de imagem. As afecções mais prevalentes foram as do sistema nervoso central, sobretudo doença do disco toracolombar e traumas vertebromedulares agudos. Nas enfermidades neurológicas, o tratamento foi considerado eficaz quando os pacientes foram capazes de recuperar a deambulação e para as lesões medulares, quando houve melhora clínica do quadro neurológico avaliado por meio de escores. O sucesso obtido nos quatro segmentos medulares foi de 69,5\%. Nas enfermidades osteomusculares, $47 \%$ dos cães apresentavam lesões no joelho e 44\% displasia coxofemoral (DCF). Adotou-se a escala analógica visual (EAV) de locomoção para definir o sucesso do tratamento nestas doenças, que foi de 52,8\%. As técnicas que mais se associaram à AP manual foram, por ordem decrescente, a eletroacupuntura, a ozonioterapia e o LASER. O número de sessões de AP foi em média de 7,6 $\pm 3,5$. Conclui-se que a AP e técnicas afins melhoraram o escore de déficit neurológico nas doenças neurológicas avaliadas quando usadas de forma isolada e quando associadas à medicina convencional.

Palavras-chave: eletroacupuntura; disco intervertebral; osteoartrose; dor crônica.

\section{Abstract}

This retrospective study evaluated the clinical outcome of 181 dogs with neurologic and 
musculoskeletal diseases treated with acupuncture and related therapies at a rehabilitation service from 2013 to 2015. The diagnosis was based on physical, neurological and orthopedic examination, and radiography, MRI or CT. Neurological cases were the most prevalent, particularly intervertebral disk disease and spinal cord acute trauma. Treatment was considered successful in neurological cases when animals regained independent locomotion or in cases of spinal disease, when neurological scores changed from V, IV or III to II or I. The success achieved in the four spinal cord segments was $69.5 \%$. For musculoskeletal diseases, $47 \%$ of the dogs had knee injuries and $24 \%$ had hip dysplasia. The visual analogue scale (VAS) of locomotion was adopted to define the success of treatment in these diseases, which was 52.8\%. The techniques most associated with manual AP were in descending order electroacupuncture, ozone therapy and LASER. The mean number of AP sessions was 7.6 \pm 3.5 . We concluded that AP and related techniques were effective to treat neurological diseases in dogs when used isolated or associated with conventional medicine.

Keywords: electroacupuncture, intervertebral disc, osteoarthrosis, chronic pain.

Recebido em: 13 de dezembro de 2016

Aceito em: 13 de novembro de 2017

\section{Introdução}

A acupuntura (AP) é uma das formas de terapias dentro da Medicina Tradicional Oriental, em que o tratamento se faz com o uso de agulhas, visando um estímulo de pontos específicos do corpo, denominados acupontos. Essa técnica apresenta diversas aplicações clínicas dado o seu amplo mecanismo de ação que envolve efeitos no sistema neuroendócrino ${ }^{(1)}$. Dentre as técnicas utilizadas para estimular os pontos de AP, destacam-se o uso de agulha simples, eletroacupuntura (EA), laserpuntura, ozoniopuntura, implante de ouro em acupontos, farmacopuntura, moxabustão, hemopuntura e respectivas associações ${ }^{(2-7)}$.

Diversos estudos na medicina veterinária comprovaram os efeitos terapêuticos da AP em distintas enfermidades. Em um estudo sobre o uso de implante de ouro em acupontos, observou-se redução de $65 \%$ da dor causada pela displasia coxofemoral (DCF) versus $39 \%$ nos animais tratados com placebo ${ }^{(5)}$. A mobilidade melhorou e os sinais de dor reduziram em $83 \%$ de cães com DCF tratados com implante de ouro, contra $60 \%$ no grupo placebo $^{(8)}$.

Em cães com doença do disco intervertebral (DDIV) toracolombar, a associação de EA e o tratamento clínico convencional foi mais eficaz que o tratamento convencional isolado para recuperar a deambulação e percepção de dor profunda ${ }^{(9)}$. Já quando a EA foi comparada à cirurgia tardia em animais com grande comprometimento neurológico, $79 \%$ dos cães portadores de discopatia toracolombar de graus IV e V tratados com EA reabilitaram-se quanto à locomoção, contra $40 \%$ nos submetidos à cirurgia descompressiva realizada após $72 \mathrm{~h}$ de início dos sinais de perda nociceptiva ${ }^{(10)}$.

Em estudos sobre o uso de AP em enfermidades neurológicas causadas por vírus, a AP foi mais eficiente que o tratamento convencional para reverter os déficits neurológicos em animais portadores de sequelas de cinomose $^{(11)}$. Quando associado à eletroestimulação, esse mesmo tratamento foi eficaz para tratar a maioria dos cães portadores de cinomose com sequelas neurológicas, como paraplegia ou quadriplegia, retenção urinária, déficits de nervos cranianos e alterações funcionais do sistema nervoso central (SNC), melhorando também a mioclonia ${ }^{(12)}$. 
A EA é a técnica mais empregada para analgesia, pois associa o efeito mecânico da agulha ao elétrico e alivia a dor central e periférica ${ }^{(13)}$. A qualidade e intensidade do efeito hipoalgésico são influenciadas pela escolha dos acupontos e forma de estimulação, uma vez que a frequência determina a classe de neuropeptídeos liberados no $\mathrm{SNC}^{(14)}$. A EA de baixa frequência $(2 \mathrm{a} 8 \mathrm{~Hz})$ estimula as fibras nociceptivas do tipo III e IV e as pequenas fibras motoras e induz a liberação no SNC de endorfina, $\beta$-encefalina e endomorfina, o que resulta em sensação de parestesia e contração muscular ${ }^{(15)}$. Este parâmetro pode ser utilizado para tratar lesões medulares que resultem em hiperreflexia detrusora em pacientes com lesão medular e doenças musculoesqueléticas ${ }^{(16)}$.

As altas frequências (100 a $200 \mathrm{~Hz}$ ) estimulam fibras aferentes do tipo II, com consequente liberação de dinorfina, serotonina, epinefrina e norepinefrina pelo SNC, o que leva à sensação de parestesia sem contração muscular e gera analgesia local por mecanismos medulares segmentares ${ }^{(13,17)}$. A EA em frequência mista (baixa e alta) de forma sequencial e alternada libera diferentes opioides endógenos, com ação sinérgica propiciando melhor resposta analgésica ${ }^{(18,19)}$. O estímulo de $2 \mathrm{~Hz}$ é mediado pelos receptores $\mu$ e $\delta$; o de $30 \mathrm{~Hz}$ por $\mu, \delta$ e k; e o de $100 \mathrm{~Hz}$ pelo $\mathrm{k}^{(20)}$.

A laserpuntura é uma técnica não invasiva que consiste no uso de LASER em acupontos e que apresenta efeito anti-inflamatório e analgésico em cães ${ }^{(21)}$ e gatos $^{(22)}$ e é indicada para tratar a dor em animais que não toleram a AP manual. A ozonioterapia é uma técnica promissora para tratar a dor, uma vez que a insuflação intra-retal de ozônio e a aplicação de ozônio nos acupontos (ozoniopuntura), foram tão eficazes como o meloxicam para analgesia pós-operatória em cadelas submetidas à ovariohisterectomia ${ }^{(23)}$.

A injeção de fluidos nos acupontos prolonga o estímulo, sendo mais rápida e adequada para animais que não podem ser contidos pelo tempo necessário para a manutenção das agulhas ou a aplicação da EA. A aquapuntura é a injeção de água destilada ou solução de $\mathrm{NaCl}$ a $0,9 \%$ nos acupuntos ${ }^{(24,25)}$ e a farmacopuntura é a administração de subdoses de fármacos em pontos de AP, o que potencializa o efeito do fármaco, minimiza os efeitos adversos e reduz os $\operatorname{custos}^{(26-28)}$. O implante de fragmentos de ouro estimula prolongadamente os acupontos, para tratar doenças crônicas, como as síndromes dolorosas ósseas ou osteoartrose $(\mathrm{OA})$ e $\mathrm{DCF}^{(29)}$. O implante também diminui a intensidade das convulsões em cães ${ }^{(30)}$.

Este estudo realizou um levantamento retrospectivo de cães com doenças neurológicas e/ou osteomusculares atendidos em serviço de reabilitação veterinária e controle de dor crônica durante o período de 2013 a 2015, num total de 181 casos. Para tal, objetivou-se caracterizar o perfil epidemiológico dos animais e avaliar a eficácia da AP e métodos afins no tratamento dessas doenças e respectiva evolução clínica.

\section{Materiais e Métodos}

O estudo foi aprovado pela Comissão de Ética no Uso de Animais (CEUA) da instituição, sob o protocolo $\mathrm{n}^{\mathrm{o}} 150 / 2014$. Todos os proprietários autorizaram a realização do estudo em seus animais por meio de um termo de consentimento.

Categorizaram-se os cães atendidos no serviço de reabilitação e dor crônica da instituição durante o período de abril de 2013 a fevereiro de 2015 segundo: sexo, raça, idade, peso, tipo de doença e tipo de tratamento em cada sessão (técnicas de AP e suas associações), tratamento convencional concomitante e 
evolução clínica. A avaliação dos animais baseou-se no exame físico e exames complementares, como diagnóstico por imagem, no caso radiografia, tomografia computadorizada (TC), ressonância nuclear magnética (RNM) e eletroneuromiografia (ENMG), quando disponíveis e de acordo com a necessidade.

Selecionaram-se os animais de acordo com as principais causas que originam enfermidades debilitantes, sendo estas de natureza neurológica ou osteomuscular. A maioria das sessões terapêuticas foram realizadas uma vez por semana, durante aproximadamente 20 minutos e o período máximo de avaliação foi de 24 semanas. Em cada sessão realizou-se um novo exame neurológico e/ou ortopédico para avaliar o grau de melhora ou piora em relação à consulta anterior. Excluíram-se os pacientes oncológicos para melhor padronizar os casos e animais que apresentavam outras comorbidades, ou cujo tratamento convencional foi modificado, em relação à primeira avaliação.

Diagnosticou-se o tipo de doença que motivou a queixa principal neurológica ou osteomuscular. Em cada tipo, categorizaram-se diagnósticos específicos. As doenças neurológicas foram classificadas em: 1 Medulares ; 2 - Encefálicas; 3 - Lesões do sistema nervoso periférico (SNP) e junção neuromuscular (JNM): nervos, gânglios e músculos e 4 -Enfermidades infecciosas do SNC.

As lesões medulares foram classificadas de acordo com o exame neurológico e de imagem em: 1) DDIV, por diagnóstico definitivo com RNM; 2) Mielopatia segmentar transversa compressiva, por lesão na medula localizada em um segmento vertebral específico - incluíram-se nesse grupo os casos sugestivos de DDIV, mas apenas diagnosticados com radiografia e exame neuroclínico; 3) Mielopatia segmentar transversa não compressiva, quando não havia imagem de compressão, mas apenas lesão focal e segmentar - os casos de tromboembolismo fibrocartilaginoso (TEFC) ou mielopatia isquêmica presumida (MIP) foram diagnosticados com RNM e nos casos de mielopatia degenerativa o diagnóstico presuntivo foi por exclusão com RNM, uma vez que este só é definitivo com exame histopatológico post-mortem; e 4) Trauma raquimedular, pela presença de imagens radiográficas ou RNM de fraturas vertebrais e luxações.

Definiu-se um critério de sucesso para cada tipo de lesão neurológica comparando o exame neurológico antes e após o tratamento. Estes critérios estão resumidos na Tabela 1 e a graduação específica de cada tipo de lesão é explicada nas tabelas seguintes.

Para avaliar os cães com lesões da coluna cervical, utilizou-se a classificação proposta por Joaquim e Luna $^{(31)}$, adaptada de Bergman et al. ${ }^{(32)}$ (Tabela 2). Os cães com lesões toracolombares foram classificados de acordo com o grau de lesão medular proposto por Joaquim et al. ${ }^{(10)}$ (Tabela 3). Considerou-se o tratamento bem sucedido em casos de lesões medulares apenas quando houve redução da classificação de graus V, IV ou III para graus II, I e zero.

Tabela 1 - Critérios de sucesso do tratamento com base no exame neurológico para cada tipo de doença neurológica avaliado pelo veterinário

\begin{tabular}{ccc}
\hline Doença Neurológica & Insucesso & Sucesso \\
\hline Medular ${ }^{[1]}$ & V, IV, III & II, I, sem alteração \\
Encefálica & III, II & I \\
SNP & III, II & I \\
Infecciosa & escala adaptada de & Santos \\
\end{tabular}

[1] Também se considerou sucesso quando as lesões de graus II ou I melhoraram para I ou 0. 
Tabela 2 - Graduação das lesões medulares cervicais (adaptada de Bergman et al. (32) $^{(32)}$

\begin{tabular}{cc}
\hline Graduação & Sinais clínicos \\
\hline I & Cervicalgia leve \\
II & Cervicalgia recorrente (paresia não ambulatória) \\
III & Cervicalgia com déficits neurológicos (paresia não ambulatória) \\
IV & Tetraparesia não ambulatória \\
V & Tetraplegia (sem dor profunda) \\
\hline
\end{tabular}

Fonte: adaptada de Bergman et al. ${ }^{(32)}$

Tabela 3 - Graduação das lesões medulares toracolombares em pacientes com doença do disco intervertebral (DDIV)

\begin{tabular}{|c|c|}
\hline Graduação & Sinais clínicos \\
\hline I & Toracolombalgia leve, moderada ou intensa, sem déficits neurológicos \\
\hline II & $\begin{array}{c}\text { Discreta incoordenação, capacidade de sustentar o próprio peso mantida, episódios } \\
\text { recorrentes de dor, déficit de propriocepção, reflexos espinhais normais ou } \\
\text { aumentados }\end{array}$ \\
\hline III & $\begin{array}{r}\text { Intensa incoordenação, perda da capacidade de sustentar o próprio peso, déficit de } \\
\text { propriocepção, reflexos espinhais normais ou aumentados }\end{array}$ \\
\hline IV & $\begin{array}{r}\text { Perda da função motora, ausência de propriocepção, } \\
\text { reflexos espinhais normais ou aumentados, resposta a dor profunda mantida }\end{array}$ \\
\hline V & $\begin{array}{r}\text { Sinais de grau IV adicionados de perda do controle da micção } \\
\text { e ausência de dor profunda (nocicepção) }\end{array}$ \\
\hline
\end{tabular}

Fonte: Joaquim et al. ${ }^{(10)}$

Diagnosticaram-se as lesões encefálicas pelo exame neurológico e quando necessário RNM, TC e/ou exame de líquido cefalorraquidiano para descartar outras patologias. Adotou-se a graduação da Tabela 4 para avaliar a evolução da doença. O tratamento foi considerado bem-sucedido quando houve redução da classificação de grau III ou II para grau I, isto é, quando desapareceram os sinais clínicos da enfermidade encefálica, tais como incoordenação e lesões de nervos cranianos.

Tabela 4 - Graduação das lesões encefálicas

\begin{tabular}{|c|c|}
\hline Graduação & Sinais clínicos \\
\hline I & Anda, propriocepção presente, sem alterações de nervos cranianos \\
\hline II & $\begin{array}{c}\text { Andar incoordenado, propriocepção ausente, } \\
\text { retorno parcial dos reflexos dos nervos cranianos }\end{array}$ \\
\hline III & Ataxia, lesão de nervo(s) craniano(s), propriocepção ausente \\
\hline
\end{tabular}

As doenças do SNP foram diagnosticadas pelo exame neuroclínico, radiografia (para exclusão de outras lesões) e exame complementar com ENMG (padrão ouro). Adaptou-se a classificação da Tabela 5 e considerou-se sucesso quando os graus III ou II reduziram para grau I, isto é, quando a paresia/paralisia evoluiu para deambulação, com retorno da função do membro e normalização da função dos nervos periféricos.

Com relação à cinomose, a mesma foi a única enfermidade infecciosa diagnosticada, sendo o diagnóstico clínico associado a PCR (reação em cadeia da polimerase) para detecção do vírus na urina. Para tal, incluíram-se os animais cujos sinais clínicos se caracterizavam por sequelas neurológicas decorrentes desta enfermidade viral, com sinais multifocais como paresias, ataxia, sinais vestibulares e cerebelares, alteração de nervos cranianos, mioclonia e sinais tálamo-corticais ${ }^{(33)}$. Incluíram-se os pacientes que 
apresentaram estabilização dos sinais neurológicos e normalização do hemograma, no mínimo um mês antes do início do tratamento com AP. Para avaliar os pacientes e verificar se o tratamento apresentou sucesso, adaptou-se a escala (Tabela 6) de avaliação neurológica para cinomose preconizada por Santos $^{(12)}$.

Tabela 5 - Graduação das lesões do sistema nervoso periférico (SNP)

\begin{tabular}{|c|c|}
\hline Graduação & Sinais clínicos \\
\hline I & Deambulação, propriocepção presente, sem alterações de nervos periféricos \\
\hline II & Dá alguns passos, reflexos segmentares normais, propriocepção ausente \\
\hline III & $\begin{array}{c}\text { Não anda (paresia não ambulatória/paraplegia), hiporreflexia dos nervos } \\
\text { periféricos, propriocepção ausente }\end{array}$ \\
\hline
\end{tabular}

Tabela 6 - Critérios de sucesso do tratamento com acupuntura de cães com sequelas neurológicas decorrentes de cinomose com base no exame neurológico (sinais clínicos)*

\begin{tabular}{|c|l|}
\hline Graduação & Paralisia/ Paraparesia \\
\hline I & Deambulação Funcional \\
\hline II & Animal atáxico - caminha com incoordenação \\
\hline III & Animal parético - fica em estação, mas não caminha; \\
\hline IV & Animal parético - não fica em estação, nem se levanta; \\
\hline V & Animal paralitico - sem dor profunda e com os sinais do grau IV \\
\hline Graduação & l. \\
\hline I & Animal sem envolvimento de nervos cranianos \\
\hline II & Animal com envolvimento de um nervo craniano \\
\hline III & Animal com envolvimento de um ou mais nervos cranianos \\
\hline Graduação & Sistema Nervoso - Encéfalo \\
\hline I & Normal \\
\hline II & Alteração comportamental \\
\hline III & Crises convulsivas \\
\hline Graduação & Mioclonia \\
\hline I & Ausente \\
\hline II & Apenas em momentos de agitação \\
\hline III & Presente - leve \\
\hline IV & Presente - moderada \\
\hline V & Presente - intensa \\
\hline Graduação & Sistema geniturinário \\
\hline I & Normal \\
\hline II & Retenção urinária ou \\
& Incontinência urinária com relaxamento de esfincter \\
\hline
\end{tabular}

Fonte: Santos $(12)$

*Para fins de análise estatística, a ficha neurológica foi preenchida considerando zero para ausência do sinal avaliado e um para presença do mesmo sinal. A graduação da escala foi realizada de um a três ou de um a cinco de acordo com cada item. Considerou-se cura quando o animal apresentou escore I até o final do tratamento, exceto no item mioclonia, no qual foi considerada resposta positiva quando o animal apresentava redução do grau IV ou V para os graus I, II ou III.

As doenças osteomusculares foram classificadas em: 1 - Displasia coxofemoral (DCF); 2 - Lesões na articulação femorotibiopatelar (ruptura parcial ou total do ligamento cruzado cranial - RLCCr e luxação patelar); 3 - outras OA (doença articular degenerativa - DAD - local e/ou generalizada); 4 - Fratura óssea. Nos casos osteomusculares, para cada tipo de doença diagnosticou-se o grau de lesão por radiografia, TC 
e RNM. Para avaliar estes casos, utilizou-se a EAV de locomoção - linha com 100 mm de comprimento, na qual a extremidade esquerda representa a melhor ("zero") e a direita a pior condição possível ("não anda"). Considerou-se sucesso no tratamento quando o valor diminuiu para $\leq 33$.

Os pacientes foram controles deles mesmos e para tal cotejaram-se os dados do primeiro dia de tratamento, ou seja, antes do início da terapia proposta, com os resultados observados após o tratamento, bem como a evolução do quadro clínico ao longo do tempo.

$\mathrm{O}$ tratamento principal de todos os pacientes incluiu técnicas associadas à AP como EA, laserterapia e ozonioterapia, farmacopuntura, implante de ouro e moxabustão. Além do tratamento principal, categorizaram-se três tipos adicionais de tratamento: 1) Analgésicos e adjuvantes analgésicos, como antiinflamatórios não esteroidais e esteroidais, opioides, amitriptilina, amantadina, gabapentina, nutracêuticos articulares, estimulação elétrica nervosa transcutânea (TENS), magnetoterapia e terapia física antiálgica; 2) Cirúrgico: pacientes que fizeram cirurgia para descompressão da medula e para casos de RLCCr; 3) Fármacos complementares específicos para afecções concomitantes: anti-inflamatórios, antibioticoterapia, vasodilatadores (enalapril) e suplementação hormonal como, por exemplo, para hipotireoidismo. Nenhum outro tipo de fármaco foi utilizado, sendo que os corticoides, quando utilizados, foram em animais que já estavam sob medicação, em doses apenas anti-inflamatórias e cuja terapia foi suprimida nas duas semanas iniciais de tratamento pelo serviço de reabilitação e dor crônica.

\section{Resultados}

Avaliaram-se 254 animais, dos quais se selecionaram 181 baseados nos critérios de inclusão e exclusão anteriormente citados. Predominaram as fêmeas (Figura 1-A) e os cães sem raça definida (SRD) (Figura 1-B). Os animais foram distribuídos de acordo com classificação internacional(34) em três faixas etárias (em anos): jovem $(\leq 1)$, adulto (entre 1 e 10) e idoso $(\geq 10)$ (Figura 2-A). Em função do seu porte (kg), os pacientes foram divididos em: pequeno $(\leq 10)$, médio (entre 10 e 25$)$ e grande ( $\geq 25)$ (Figura 2-B). As enfermidades neurológicas (80\%) prevaleceram em relação às osteomusculares (20\%).

Nas enfermidades neurológicas, as medulares (82\%) foram as mais prevalentes, seguidas pelas infecciosas (8\%). Das 119 lesões medulares, 29 (24\%) foram diagnosticadas com RNM, das quais quatro animais foram atendidos após procedimento de cirurgia descompressiva. Estas lesões foram divididas em: 1) DDIV: 22 casos - 19\%; 2) Mielopatia segmentar transversa compressiva: 79 casos (65\%) com imagem radiográfica sugestiva de DDIV e os outros 35\% com diagnóstico por RNM e/ou TC; 3) Mielopatia segmentar transversa não compressiva: quatro casos (3\%), três de TEFC, dois casos diagnosticados com RNM e o outro com TC e mielografia, e um cão com provável mielopatia degenerativa (RNM); 4) Trauma vertebromedular: 16 casos (13\%) dos quais quatro diagnosticados com RNM e um com TC, sendo o restante diagnosticado com radiografia. A Tabela 7 apresenta estes casos distribuídos por segmento vertebral. 

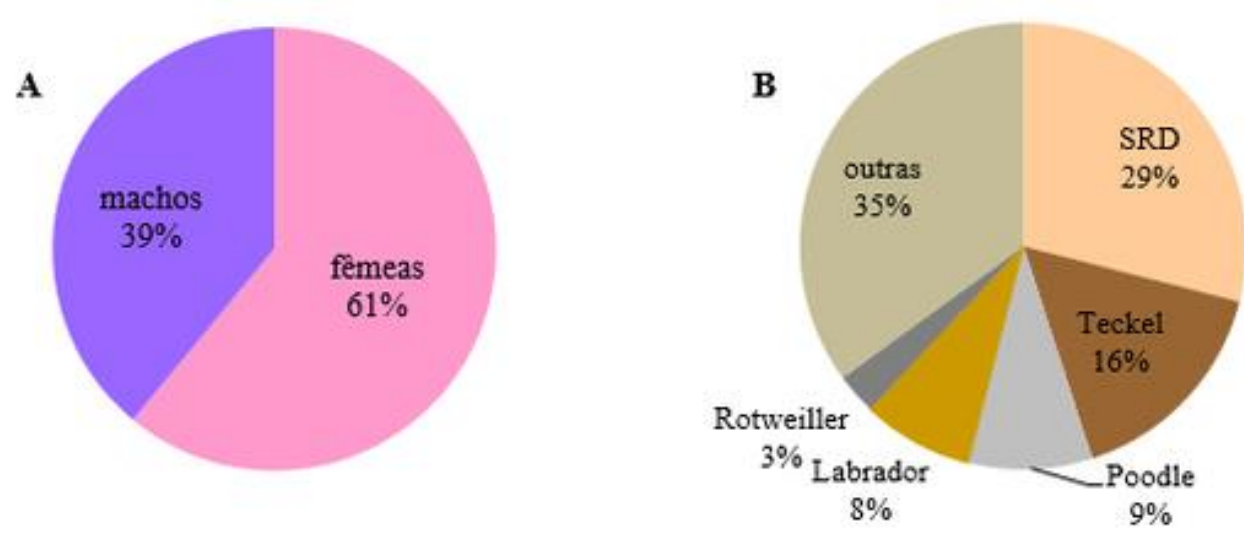

Figura 1 - Prevalência (\%) de sexo (A) e raça (B) dos 181 cães com doenças neurológicas e osteomusculares tratados com acupuntura (AP) e outras terapias por até 24 semanas.

A

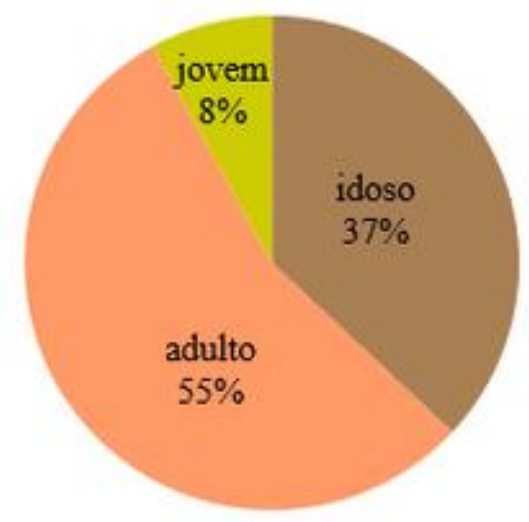

B

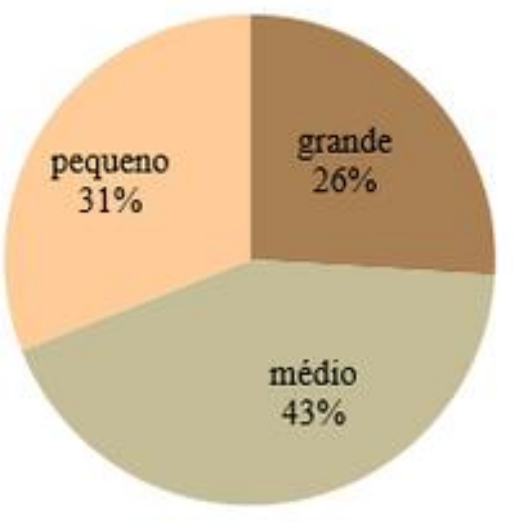

Figura 2 - Prevalência (\%) das faixas etárias (A) e porte (B) dos 181 cães com doenças neurológicas e osteomusculares tratados com acupuntura (AP) e outras terapias por até 24 semanas.

Tabela 7 - Percentagem e número de animais com lesões medulares distribuídos por segmento anatômico nos animais com doenças neurológicas $(\mathrm{n}=119)$

\begin{tabular}{|c|c|c|c|c|c|}
\hline $\begin{array}{c}\text { Segmento } \\
\text { medular }\end{array}$ & $\%\left(\mathbf{n}^{\circ}\right)$ cães & DDIV & $\begin{array}{c}\text { Mielopatia } \\
\text { segmentar } \\
\text { transversa } \\
\text { compressiva }\end{array}$ & $\begin{array}{c}\text { Mielopatia } \\
\text { segmentar } \\
\text { transversa não } \\
\text { compressiva }\end{array}$ & Trauma \\
\hline C1-C5 & $23 \%(27)$ & $15 \%(11)$ & $74 \%(20)$ & - & $11 \%(3)$ \\
\hline C6-T2 & $5 \%(6)$ & - & $67 \%(4)$ & $33 \%(2)$ & - \\
\hline T3-L3 & $48 \%(57)$ & $21 \%(12)$ & $63 \%(36)$ & $2 \%(1)$ & $14 \%(8)$ \\
\hline L4-S3 & $24 \%(29)$ & $3 \%(1)$ & $86 \%(25)$ & $4 \%(1)$ & $7 \%(2)$ \\
\hline
\end{tabular}

$\%$ em relação ao total da linha (em cada segmento vertebral)

Nas lesões medulares, prevaleceram as toracolombares, seguida das lombossacras (Figura 3-A). De acordo com a avaliação neurológica e os critérios mencionados, registraram-se as taxas de sucesso para cada segmento (Figura 3-B). O sucesso geral de tratamento, agrupando-se os pacientes dos quatro segmentos medulares, foi de $69,5 \%$. 
B
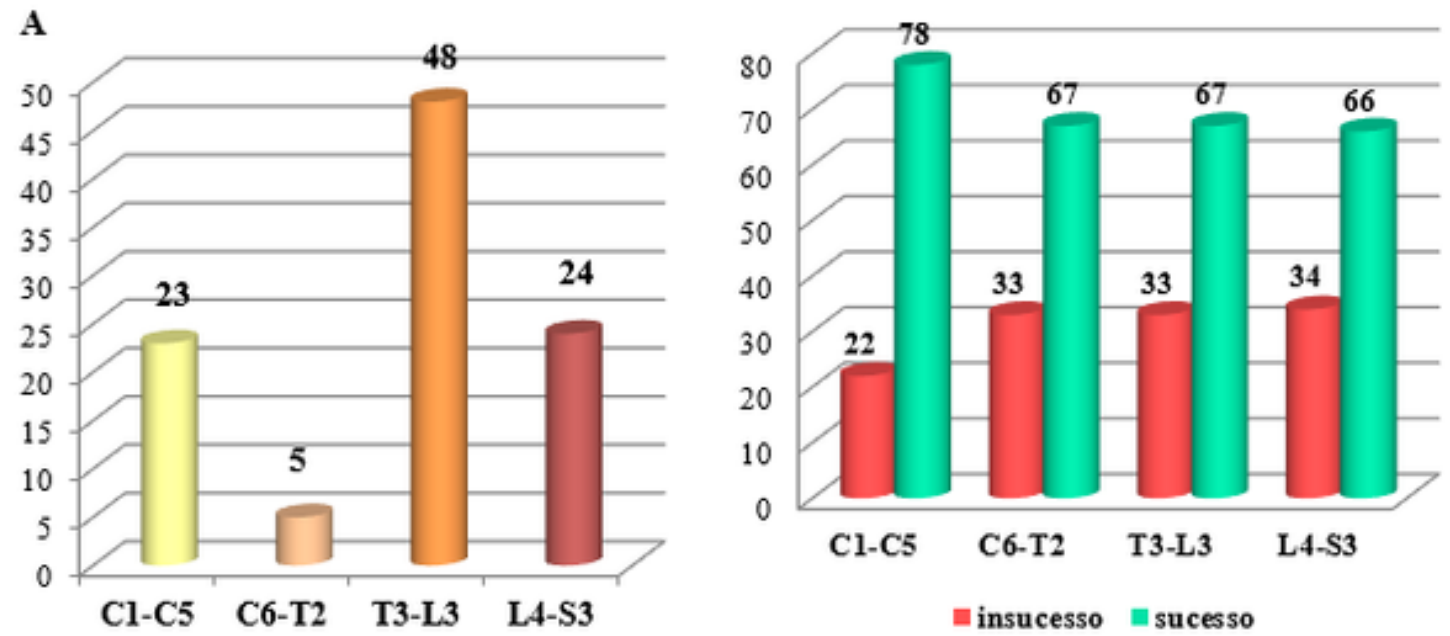

Figura 3 - A: Prevalência (\%) das lesões por cada segmento nos cães (n=119) com doenças neurológicas medulares tratados com acupuntura (AP) e outras terapias; B: Percentagem de sucesso obtido após o tratamento com acupuntura (AP) por até 24 semanas e outras terapias para os quatro segmentos nos cães com doenças neurológicas medulares $(\mathrm{n}=119)$.

Ao se comparar o grau neurológico pré e pós-tratamento para cada lesão medular nos quatro segmentos ( $\mathrm{n}=119)$ obtiveram sucesso: cinco (28\%) dos 18 cães classificados em grau V; 17 (65\%) dos 26 cães em grau IV; 47 (86\%) dos 55 em grau III (Figura 4).

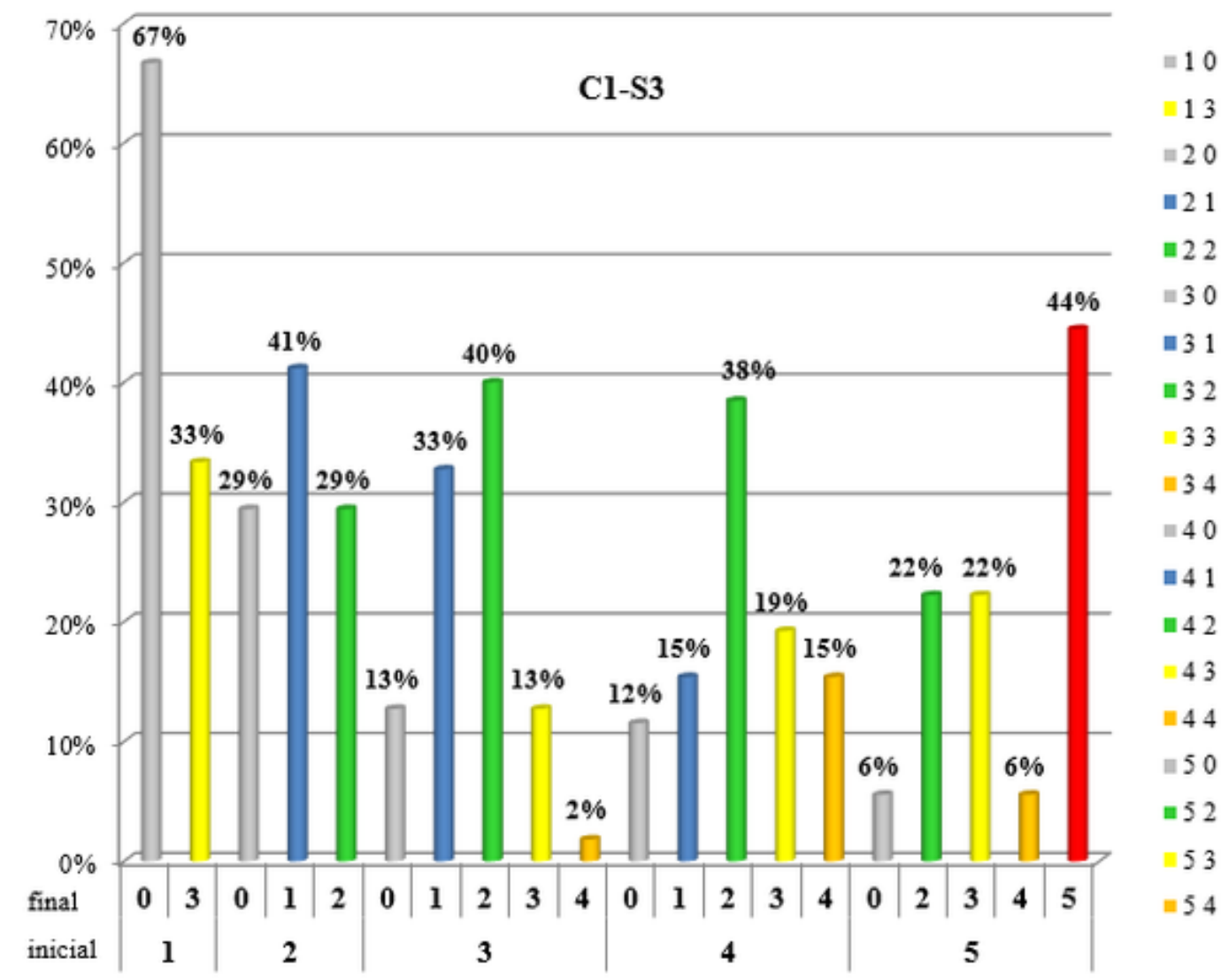

Figura 4 - Percentual dos animais segundo o grau neurológico da lesão medular antes e após o tratamento com acupuntura (AP) e outras terapias, por até 24 semanas, para os quatro segmentos vertebrais $(n=119)$ [A coluna da direita expressa a cor da classificação neurológica antes e após o final tratamento. A abscissa representa a evolução da porcentagem de animais com cada grau de lesão neurológica antes (linha inferior) e após (linha superior) o tratamento]. 
A

\section{Cl-C5}

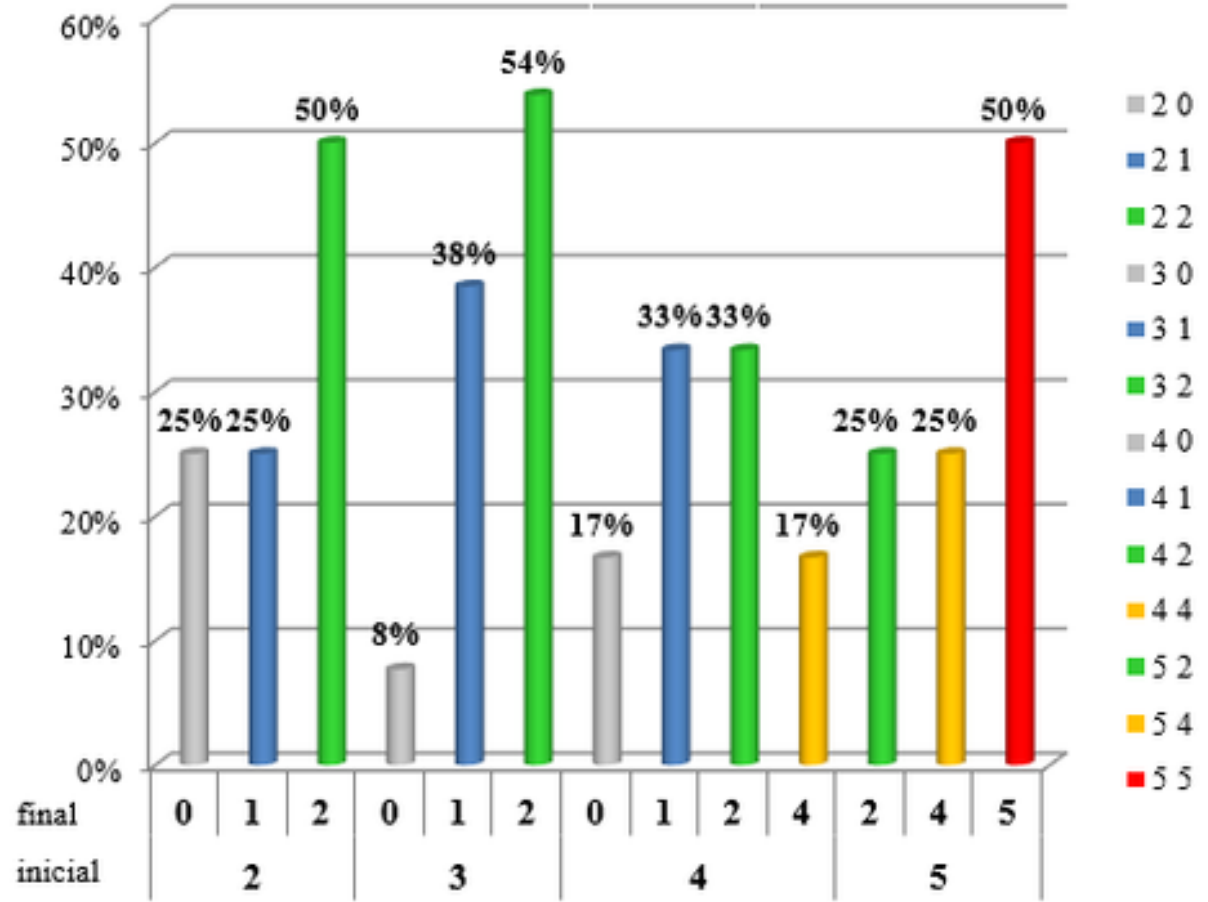

B

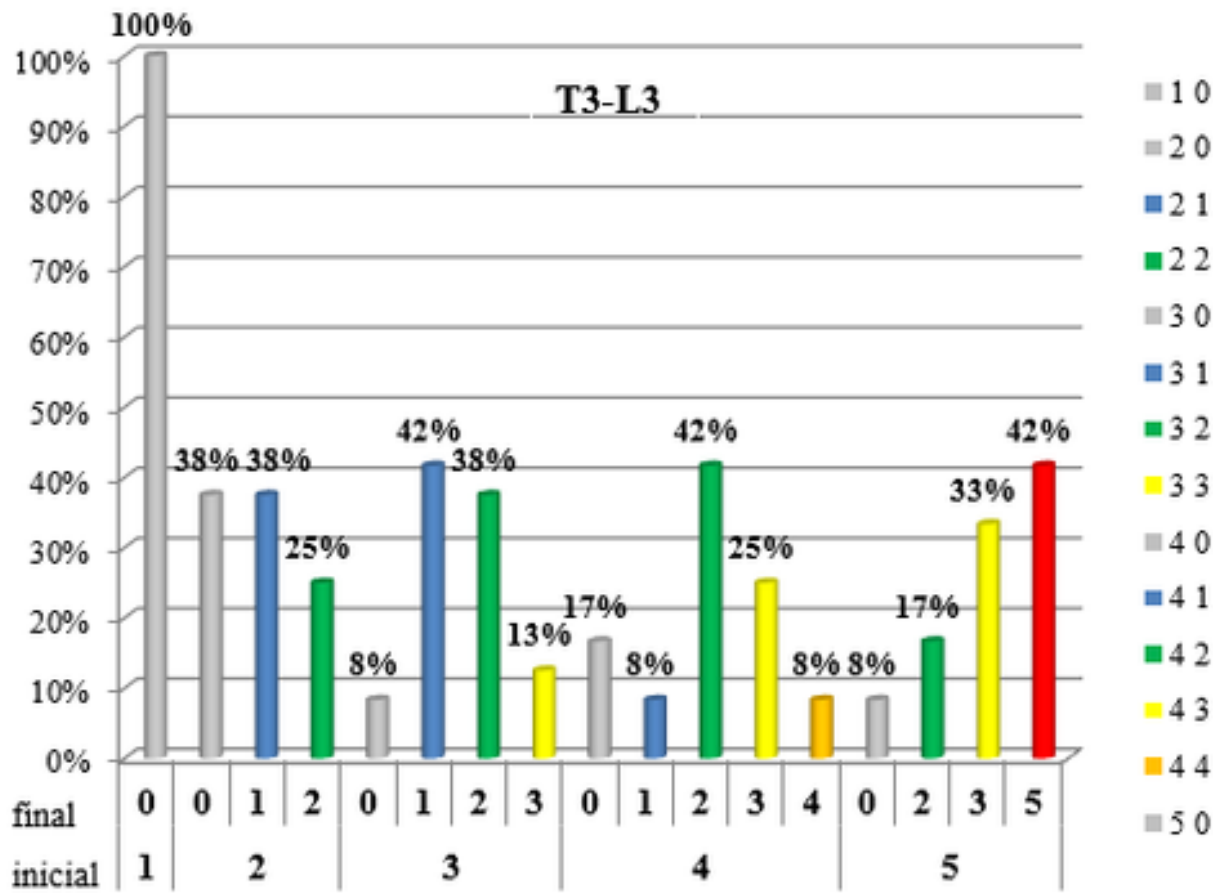

Figura 5 - Percentual dos animais segundo o grau neurológico da lesão medular antes e após o tratamento com acupuntura (AP) e outras terapias, por até 24 semanas, para o segmento cervical $(n=27)(A)$ e toracolombar $(\mathrm{n}=57)(B)$. [A coluna da direita expressa a cor da classificação neurológica antes e após o final tratamento. A abscissa representa a evolução da porcentagem de animais com cada grau de lesão neurológica antes (linha inferior) e após (linha superior) o tratamento].

No segmento cervical ( $\mathrm{n}=27)$ houve sucesso em um (25\%) dos quatro cães classificados em grau V; cinco $(83 \%)$ dos seis em grau IV e todos os 13 (100\%) em grau III melhoraram (Figura 5-A). No segmento toracolombar $(n=57)$ obtiveram sucesso três $(25 \%)$ dos 12 cães de grau V; oito (67\%) dos 
12 em grau IV e 21 (88\%) dos 24 em grau III (Figura 5-B). No segmento cervicotorácico ( $\mathrm{n}=6$ ), foi bem sucedido um dos dois (50\%) casos que estavam em grau IV e dois dos três (50\%) em grau III (Figura 6-A). No segmento lombossacro $(\mathrm{n}=29)$ um dos dois $(50 \%)$ casos que estavam em grau V; três dos seis (50\%) em grau IV e 11 dos 15 (63\%) que estavam em grau III (Figura 6-B).
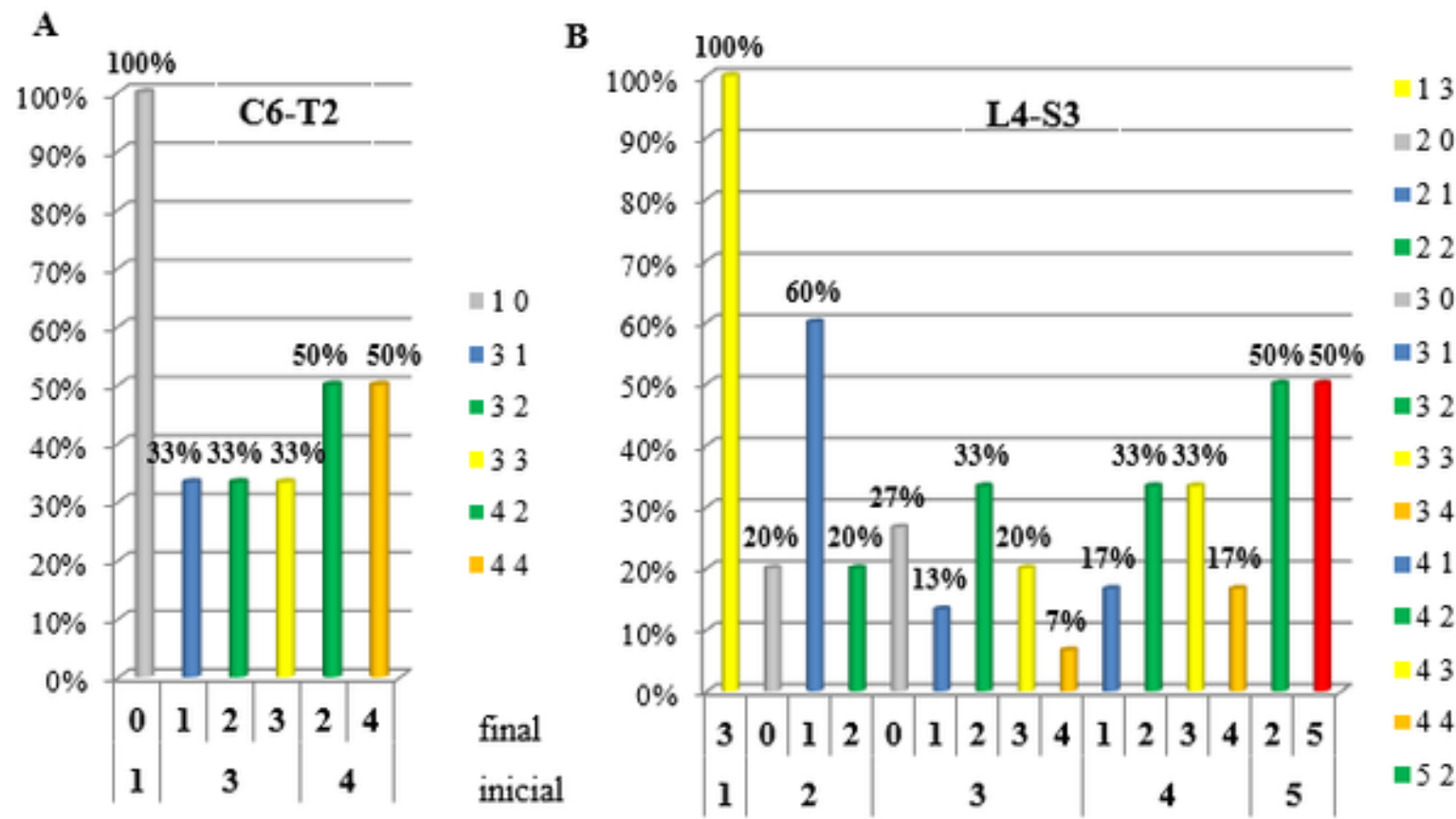

Figura 6 - Comparação em percentual dos animais com o grau neurológico da lesão medular antes e após o tratamento com acupuntura (AP) e outras terapias, por até 24 semanas, para o segmento cervicotorácico $(\mathrm{n}=6)$ (A) e lombossacro ( $n=29)$ (B) [A coluna da direita expressa a cor da classificação neurológica antes e após o final tratamento. A abscissa representa a evolução da porcentagem de animais com cada grau de lesão neurológica antes (linha inferior) e após (linha superior) o tratamento].

Das quatro lesões encefálicas, duas eram de síndrome vestibular e duas encefálicas (cognitiva). Em metade (50\%) dos cães, o tratamento foi bem sucedido. Das sete lesões de SNP/JNM, cinco foram diagnosticadas com ENMG, das quais duas de polirradiculoneurite (entre três), uma de polineuropatia axonal distal do rottweiller (de duas), uma de polineuropatia e outra de polimiosite imunomediada. $\mathrm{O}$ tratamento apresentou sucesso em $71 \%$ dos cães. Das 15 doenças infecciosas, todas foram diagnosticadas clinicamente como cinomose, mas só três casos foram confirmados com exame laboratorial de RT-PCR positivo, sendo os outros 13 diagnosticados clinicamente baseados em sinais clínicos, sinais patognomônicos como mioclonia, entre outros. Em 53\% (8) dos animais, o tratamento foi bem sucedido.

No que concerne às enfermidades osteomusculares, 27\% dos casos só apresentavam DCF, $17 \%$ apresentavam lesões apenas no joelho e em $36 \%$ de casos duas ou mais lesões ortopédicas estavam associadas (Figura 7). Ao se considerar cada lesão de forma isolada ou associada, obteve-se $47 \%$ de lesões em joelho e $44 \%$ em DCF. 


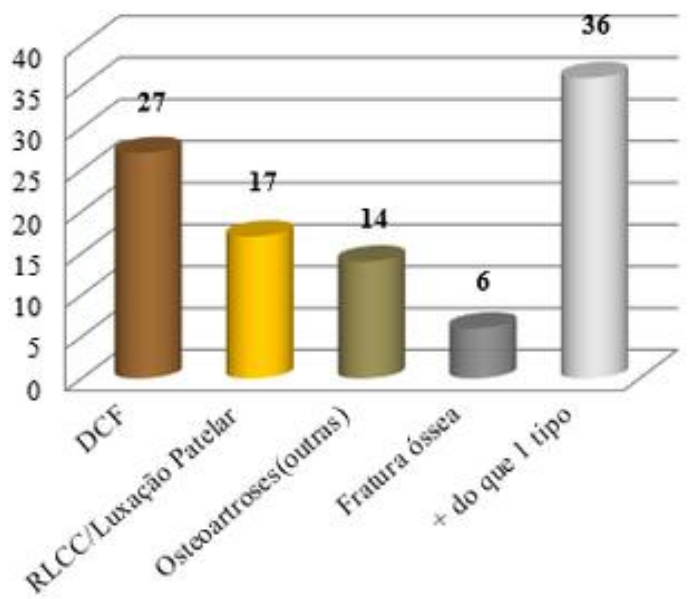

Figura 7 - Prevalência dos tipos de doenças osteomusculares (de forma isolada e associada) nos cães ( $\mathrm{n}=36$ ) tratados com acupuntura (AP) e outras terapias.

Foram diagnosticados 36 casos com radiografia e um também por ultrassonografia. No que concerne à utilização do tratamento principal para ambos os grupos tratados (doenças neurológicas e osteomusculares), a maioria das técnicas associadas à AP foram a EA, LASER e ozonioterapia. Outras técnicas afins direcionadas ao tratamento foco foram utilizadas em $38 \%$ dos casos, sobretudo a farmacopuntura e a moxabustão. A AP manual foi a técnica mais utilizada seguida da EA (Figura 8-A). A AP foi usada em $100 \%$ dos pacientes neurológicos e em $97 \%$ dos osteomusculares. A EA foi mais utilizada em lesões neurológicas $(78 \%)$ do que nas osteomusculares (33\%). A laserterapia foi mais usada em casos osteomusculares (38\%) do que nos neurológicas (19\%), bem como a ozonioterapia, realizada em $53 \%$ dos casos osteomusculares e $28 \%$ dos neurológicos. Dos tratamentos associados ao tratamento principal, os analgésicos foram os mais frequentemente utilizados (72\%) (Figura 8-B), com maior incidência em doenças osteomusculares (78\%) do que nas neurológicas (71\%). Cerca de $7 \%$ dos pacientes foram atendidos após procedimentos cirúrgicos. O número de sessões totais de AP foi em média de 7,6 63,5 .
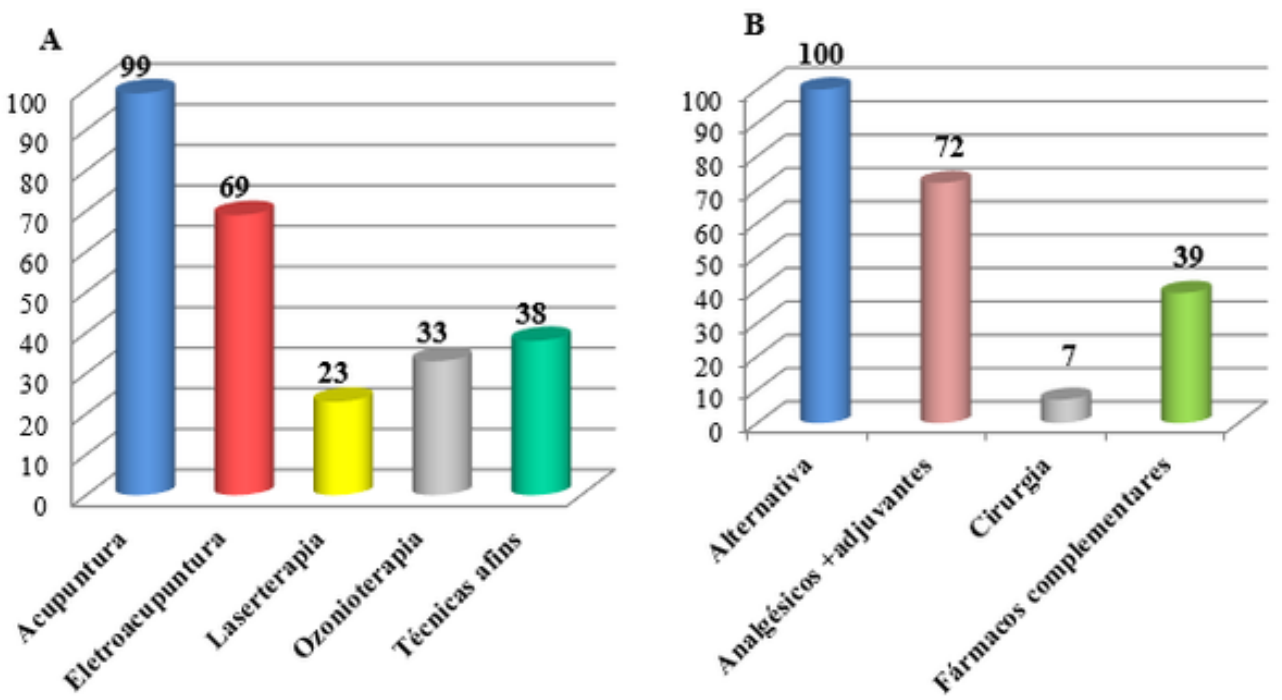

Figura 8 - Frequência (\%) de cada técnica afim à acupuntura (AP) selecionada (A) e frequência (\%) das várias terapias utilizadas (B) nos 181 animais com doenças neurológicas e osteomusculares. 


\section{Discussão}

Esse estudo demonstrou que a AP é uma ferramenta terapêutica para tratar doenças neurológicas e osteomusculares, casuística predominantemente observada nos estudos de perfil dos pacientes nesta especialidade $^{(2,7)}$, o que corrobora suas indicações em animais que apresentem doenças crônicas, com baixa resposta à terapêutica convencional e que apresentam dor e deterioração da qualidade de vida. Tal como em outros estudos retrospectivos, prevaleceram as enfermidades neurológicas, o que pode se relacionar à eficácia da AP na DDIV já destacada em diversos estudos ${ }^{(9,10)}$ e ao fato de que estes casos não respondem de forma satisfatória à terapêutica com uso da corticoterapia ${ }^{(35)}$, ou seja, tratamento clínico médico convencional.

As lesões neurológicas como discopatias, traumas medulares, neuropatias periféricas, mielopatia degenerativa, disfunção urinária/fecal de origem neurogênica e sequelas de cinomose apresentam graves sinais de incapacitação, com vários graus de paresia ou paralisia ${ }^{(2)}$. Estes achados estão de acordo com as principais indicações da técnica de AP, indicações essas que segundo a literatura seriam: 1) paralisia, paresia e dor devido à DDIV; 2) déficit de locomoção devido à espondilose, síndrome da cauda equina (SCE); 3) dor devido à DCF; 4) síndromes articulares com dor e 5) outras condições que não respondem ao tratamento convencional como epilepsia, neuropatias periféricas, síndromes dolorosas e outras ${ }^{(10,36,37)}$. Estes resultados não são espécie-específicos, já que também foram observados em felinos domésticos, com recuperação da locomoção independente, em casos de lesões medulares e redução do escore neurológico de graus V, IV ou III para graus II ou I em $67 \%$ dos casos tratados com $\mathrm{AP}^{(38)}$.

Neste estudo, as lesões medulares mais comuns foram as DDIV, como descrito anteriormente em avaliação de perfil de pacientes atendidos com $\mathrm{AP}^{(37)}$. Como observado neste estudo e em estudos anteriores $^{(9,10)}$, estes casos respondem favoravelmente à AP, pois, além desta técnica melhorar os sinais neurológicos, há uma melhora considerável na qualidade de vida da maioria dos animais. As mielopatias cervicais que prevaleceram em nosso estudo foram as DDIV e os traumas de graus IV e III, respectivamente, com sucesso de tratamento em $78 \%$ dos cães, corroborando com os achados de Joaquim e Luna ${ }^{(31)}$. No segmento lombossacro registraram-se os poucos casos de piora, que podem ser devidos à mielopatia degenerativa, para a qual a AP não é eficaz, podendo apenas retardar a evolução da doença e conferir qualidade de vida ao paciente.

O trauma raquimedular foi o terceiro padrão com melhor resposta terapêutica constatada neste estudo, tal como no estudo de Joaquim et al. ${ }^{(37)}$ Essa melhora pode dever-se aos efeitos antioxidantes, antiinflamatórios e antiapoptose da AP que promoveram a neuroproteção e a recuperação da função neural dorsal em traumas medulares em ratos ${ }^{(39)}$. Uma metanálise ${ }^{(40)}$ evidenciou que a AP neste tipo de lesões em humanos apresentou efeitos benéficos na reabilitação neurológica, na função motora e na recuperação funcional.

No segmento toracolombar, $46 \%$ dos cães com DDIV em grau V ou IV melhoraram para grau II ou I, a mesma taxa de sucesso demonstrada em estudo anterior em DDIV toracolombar, com recuperação da deambulação e da percepção de dor profunda ${ }^{(9)}$ e abaixo dos $80 \%$ reportado por Joaquim et al. ${ }^{(10)}$. Nos demais segmentos os resultados foram similares. 
Apesar de alguns casos com sequelas neurológicas de cinomose não terem sido diagnosticados por PCR, o que é uma limitação deste estudo, esses cães apresentaram sinais característicos da doença e o tratamento proporcionou uma evolução notória na melhoria dos sinais neurológicos e da qualidade de vida. $\mathrm{O}$ fato dos animais já terem se submetidos ao tratamento convencional sem melhora, valoriza o tratamento com AP, com resultados que demonstram a sua boa eficácia tal como descrito anteriormente $^{(11,12)}$. O tratamento de cães com polirradiculoneurite aguda é restrito à reabilitação fisioterápica e cuidados de suporte segundo a literatura vigente sobre o tema ${ }^{(41)}$. Neste estudo os três casos de polirradiculoneurite, com sinais de tetraparesia, foram tratados com sucesso, tal como em dois casos reportados previamente ${ }^{(42)}$, em que a AP também melhorou os sinais clínicos de tetraparesia/plegia.

A escolha entre as técnicas, sobretudo AP manual ou associada à EA, foi baseada em achados clínicos como hipotrofia muscular, lesão neurológica, tempo de paresia/ataxia e ausência ou presença de dor superficial e/ou profunda ${ }^{(43)}$. Utilizou-se o estímulo elétrico para reduzir a hipotrofia muscular, aliviar a dor e as contraturas/espasmos (em pontos gatilho) ${ }^{(44)}$. A resposta clínica ao tratamento também depende da origem e da evolução da dor. Neste estudo utilizou-se baixa frequência (5 a $20 \mathrm{~Hz})$ para tratar paresia, ataxia, fraqueza, hiperestesia e diminuição de sensibilidade, tal como descrito anteriormente $^{(43)}$, em que se obteve melhora dos quadros de paresia induzidos por discopatia toracolombar em cães. Para pacientes com dor neurológica, como as causadas por DDIV, a alta frequência (acima de $100 \mathrm{~Hz}$ ) foi a opção. Joaquim et al. ${ }^{(43)}$ também utilizaram alta frequência para melhorar a dor induzida por discopatias cervicais em cães.

Em consonância com perfis de pacientes de estudos anteriores, 20\% dos animais apresentaram doenças osteomusculares. A OA é considerada a primeira causa de dor crônica em cães e afeta $20 \%$ dos animais adultos ${ }^{(45)}$, mas segundo avaliações recentes esses dados estariam subestimados, podendo atingir as cartilagens articulares de $68 \%$ da população canina ${ }^{(46)}$. Nesse estudo, além da AP, as técnicas mais usadas em ordem decrescente foram a ozonioterapia, o LASER e a EA, como descrito anteriormente $^{(47)}$. Os efeitos benéficos da AP no tratamento de disfunções musculoesqueléticas estão associados com a analgesia secundária à liberação de endorfinas, redução da inflamação tecidual local, alívio da dor em pontos gatilho e alívio da rigidez muscular, redução da compressão articular e vasodilatação local ${ }^{(48,49)}$. A AP atua também na regulação das metaloproteinases, o que sugere que possui efeito condroprotetor ${ }^{(50)}$.

Nos pacientes com alterações musculoesqueléticas deste estudo, a EA foi usada em um terço dos casos e aparentemente nossos resultados positivos são confirmados por estudos anteriores em seres humanos com OA na articulação femorotibiopatelar, nos quais a EA diminuiu a dor e melhorou a capacidade funcional ${ }^{(51)}$ e tanto a AP como a EA reduziram a intensidade da dor, sem diferença entre as duas técnicas ${ }^{(52)}$.

Este estudo teve algumas limitações, uma delas inerente a um experimento clínico desta natureza, que é a heterogeneidade dos dados populacionais e epidemiológicos, com diferentes graduações em cada lesão e associações entre elas. Os tratamentos efetuados não incluíram sempre as mesmas técnicas terapêuticas e tipo de medicações. Como se esperaria de um estudo retrospectivo, em alguns casos o diagnóstico foi presuntivo, por ausência de exame complementar padrão ouro. Entretanto, o foco deste estudo não era avaliar o efeito da AP em cada doença específica, mas sim a melhora ou não dos sinais clínicos na população estudada, o que foi confirmado. 


\section{Conclusões}

A AP e técnicas afins foram eficientes para tratar a maioria dos cães com doenças neurológicas tanto de forma isolada, bem como associada a terapias analgésicas. Houve prevalência de doenças neurológicas em relação às osteomusculares, sobretudo as DDIV toracolombares e o trauma raquimedular agudo. A AP manual e a EA foi a associação mais frequente e os analgésicos foram a terapia adicional mais utilizada.

\section{Agradecimentos}

À Fundação de Amparo à Pesquisa do Estado de São Paulo (FAPESP) pela concessão da bolsa de mestrado (Proc. 2013/02462-1).

\section{Referências}

1. Taffarel MO, Freitas PMC. Acupuntura e analgesia: aplicações clínicas e principais acupontos. Ciência Rural. 2009;39(9):2665-2672.

2. Angeli AL, Joaquim JGF, Gama ED, Luna SPL. Outcome of 119 dogs and cats treated at the acupuncture unit of the Faculty of Veterinary Medicine and Animal Science of the University of São Paulo State, Botucatu city, Brazil. Brazilian Journal of Veterinary Research and Animal Science. 2005;42(1):68-74.

3. Cantwell SL. Traditional Chinese Veterinary Medicine: The Mechanism and Management of Acupuncture for Chronic Pain. Topics in Companion Animal Medicine. 2010;25(1):53-58.

4. Hayashi AM, Matera JM, da Silva TS, Pinto AC, Cortopassi SR. Electro-acupuncture and Chinese herbs for treatment of cervical intervertebral disk disease in a dog. Journal of Veterinary Science. 2007;8(1):95-98.

5. Jaeger GT, Larsen S, Søli N, Moe L. Double-blind, placebo-controlled trial of the pain-relieving effects of the implantation of gold beads into dogs with hip dysplasia. Veterinary Record. 2006;158(21):722-726.

6. Luna SP, Angeli AL, Ferreira CL, Lettry V, Scognamillo-Szabó M. Comparison of pharmacopuncture, aquapuncture and acepromazine for sedation of horses. Journal of Evidence-Based Complementary \& Alternative Medicine. 2008;5(3):267-272.

7. Ueda MY, Luna SPL, Joaquim JGF, Scognamillo-Szabó, MVR. Estudo retrospectivo de 1137 animais submetidos à Acupuntura na FMVZ, Unesp, Botucatu. Ars Veterinaria. 2010;26(1):6-10.

8. Jaeger GT, Larsen S, Søli N, Moe L. Two years follow-up study of the pain-relieving effect of gold bead implantation in dogs with hip-joint arthritis. Acta Veterinaria Scandinavica. 2007;49:9. DOI: 10.1186/17510147-49-9

9 Hayashi AM, Matera JM, Fonseca Pinto AC. Evaluation of electroacupuncture treatment for thoracolumbar intervertebral disk disease in dogs. Journal of the American Veterinary Medical Association. 2007;231(6):913918.

10. Joaquim JGF, Brondani JT, Luna SPL, Torelli SR, Rahal CR, Freitas FP. Comparison of decompressive surgery, electroacupuncture, and decompressive surgery followed by electroacupuncture for the treatment of dogs with intervertebral disk disease with long-standing severe neurologic deficits. Journal of the American 
Veterinary Medical Association. 2010;236(11):1225-1229.

11. Cole EF. Avaliação dos efeitos terapêuticos obtidos com a alopatia e a acupuntura no tratamento de distúrbios neurológicos decorrentes da cinomose canina [Dissertação]. Recife: Faculdade de Medicina Veterinária, Universidade Federal Rural de Pernambuco, Recife, PE. 1996. 204 p. [acesso 2017 Dez 12]. Disponível em: http://www.scielo.br/scielo.php?script=sci_nlinks\&ref=000113\&pid=S0103$8478201000020004000017 \& \operatorname{lng}=$ pt.

12. Santos BPCR. Efeito da acupuntura no tratamento de animais com sequelas neurológicas decorrentes de cinomose [Dissertação]. Botucatu: Faculdade de Medicina Veterinária e Zootecnia, Universidade Estadual Paulista, campus de Botucatu. 2013. 90 p. [acesso 2017 Dez 12]. Disponível em: repositorio.unesp.br/handle/11449/108599

13. Liu HX, Tian JB, Luo F, Jiang YH, Deng ZG, Xiong L, et al. Repeated 100 Hz TENS for the Treatment of Chronic Inflammatory Hyperalgesia and Suppression of Spinal Release of Substance P in Monoarthritic Rats. Journal of Evidence-Based Complementary \& Alternative Medicine. 2007;4(1):65-75.

14. Ulett GA, Han S, Han JS. Electroacupuncture: mechanisms and clinical application. Biological Psychiatry. 1998;44(2):129-138.

15. Zhang RX, Lao L, Wang L, Liu B, Wang X, Ren K, et al. Involvement of opioid receptors in electroacupuncture-produced anti-hyperalgesia in rats with peripheral inflammation. Brain Research. 2004;1020(1-2):12-17.

16. Prévinaire JG, Soler JM, Perrigot M, Boileau G, Delahaye H, Schumacker P, et al. Short-term effect of pudendal nerve electrical stimulation on detrusor hyperreflexia in spinal cord injury patients: importance of current strength. Paraplegia. 1996;34(2):95-99.

17. Groppetti D, Pecile AM, Sacerdote P, Bronzo V, Ravasio G. Effectiveness of electroacupuncture analgesia compared with opioid administration in a dog model: a pilot study. British Journal of Anaesthesia. 2011;107(4):612-618.

18. Chen XH, Geller EB, Adler MW. Electrical stimulation at traditional acupuncture sites in periphery produces brain opioid-receptor-mediated antinociception in rats. Journal of Pharmacology and Experimental Therapeutics. 1996;277(2):654-660.

19. Han JS, Xie GX, Ding XZ, Fan SG. High and low frequency electroacupuncture analgesia are mediated by different opioid peptides. Pain. 1984;18:S369.

20. Chen XH, Han JS. Analgesia induced by electroacupuncture of different frequencies is mediated by different types of opioid receptors: another cross-tolerance study. Behavioural Brain Research. 1992;47(2):143-149.

21. Taffarel MO, Cardoso GS, Luna SPL, Derussi AAP, Volpato R, Guaitolini CRF, et al. Preemptive analgesia with laserpuncture in dogs undergoing ovariohysterectomy. Veterinary Anaesthesia and Analgesia. 2013;40:4.

22. Marques VI, Cassu RN, Nascimento FF, Tavares RC, Crociolli GC, Guilhen RC, et al. Laser Acupuncture for Postoperative Pain Management in Cats. Journal of Evidence-Based Complementary \& Alternative Medicine. 2015;2015:653270. http://dx.doi.org/10.1155/2015/653270

23. Teixeira LR, Luna SP, Taffarel MO, Lima AF, Sousa NR, Joaquim JG, et al. Comparison of intrarectal ozone, ozone administered in acupoints and meloxicam for postoperative analgesia in bitches undergoing ovariohysterectomy. Veterinary Journal. 2013;197(3):794-799.

24. Luna SPL, Kelawala NH, Lima AFM, Saarto EE, Restitutti FC, Silva NEOF. Effect of aquapuncture on the postoperative analgesia after ovariohysterectomy in dogs. Semina: Ciências Agrárias. 2015;36(3 Supl. 
1):1979-1990.

25. Sousa NR, Luna SPL, Cápua MLB, Lima AFM, Oliveira FA, Viveiros BM, et al. Analgesia of preemptive pharmacopuncture with meloxicam or aquapuncture in cats undergoing ovariohysterectomy. Ciência Rural. 2012;42(7):1231-1236.

26. Cassu RN, Melchert A, Canoa JT, Martins PD. Sedative and clinical effects of the pharmacopuncture with xylazine in dogs. Acta Cirúrgica Brasileira. 2014;29(1):47-52.

27 Luna SPL, Angeli AL, Ferreira CL. Acupuncture or pharmacopuncture for analgesia: which one is the best? In: Proceedings of $36^{\text {th }}$ International Congress on Veterinary Acupuncture; 2010; Aarborg, Denmark. Red Hook: Curran \& Associates, 2010. p. 159-165.

28. Taffarel MO, Salgado AEP, Melo Filho EV, Teixeira LR, Fracalossi LDC, Luz MR, et al. Effects of electroacupuncture, aquapuncture and pharmacopuncture in dogs anesthetized with isoflurane and submitted to ovariohysterectomy. Arquivo Brasileiro de Medicina Veterinária e Zootecnia. 2012;64(1):23-31 .

29. Jæger GT, Stigen $\varnothing$, Devor M, Moe L. Gold Bead Implantation in Acupoints for Coxofemoral Arthrosis in Dogs: Method Description and Adverse Effects. Animals (Basel). 2012;2(3):426-436.

30. Goiz-Marquez G, Caballero S, Solis H, Rodriguez C, Sumano H. Electroencephalographic evaluation of gold wire implants inserted in acupuncture points in dogs with epileptic seizures. Research in Veterinary Science. 2009;86(1):152-161.

31. Joaquim JGF, Luna SPL. Cervical spinal injury in dogs: a retrospective study of 68 patients treated at acupuncture. In: Proceedings of $36^{\text {th }}$ International Congress on Veterinary Acupuncture; 2010; Aarborg, Denmark. Proceedings. Red Hook: Curran \& Associates, 2010. p. 159-165.

32. Bergman RL, Levine JM, Coates JR, Bahr A, Hettlich BF, Kerwin SC. Cervical spinal locking plate in combination with cortical ring allograft for a one level fusion in dogs with cervical spondylotic myelopathy. Veterinary Surgery. 2008;37(6):530-536.

33. Amude AM, Gardinali NR, Abdulack F, Negrão FJ, Arias MVB, et al. Achados clínico-patológicos em cães com encefalomielite da cinomose apresentados sem sinais sistêmicos e mioclonia. Acta Sci Vet. 2007;35(Sup.2):601-602. Disponível em http://www.ufrgs.br/actavet/35-suple2/anclivepa\%20artigo\%20neurologia.pdf, acesso em janeiro de 2018.

34. Goldston RT, Hoskins JD. Geriatria e gerontologia do cão e do gato. $2^{a}$ ed. São Paulo: Roca; 1999. 450 p.

35. Olby N. The pathogenesis and treatment of acute spinal cord injuries in dogs. Veterinary Clinics of North America: Small Animal Practice. 2010;40(5):791-807.

36. Janssens LA, Rogers PA. Acupuncture versus surgery in canine thoracolumbar disc disease. Veterinary Record. 1989;124(11):283.

37. Joaquim JGF, Luna SPL, Torelli S, Angeli AL. Acupuntura como tratamento de doenças neurológicas em cães. Revista Acadêmica, Ciência Animal. 2008;6(3):327-334. DOI: http://dx.doi.org/10.7213/cienciaanimal.v6i3.10574. Acesso em janeiro de 2018.

38. Silva NEOF, Joaquim, JGF, Luna SPL, Cápua, MLB, Santos BPR. Retrospective study of 98 cats submitted to Acupuncture at FMVZ/ UNESP - Botucatu, SP. In: Proceedings of $40^{\text {th }}$ International Congress on Veterinary Acupuncture; 2014; Florence, Italy. Hook: Curran \& Associates. p. 219-220.

39. Jiang SH, Tu WZ, Zou EM, Hu J, Wang S, Li JR, et al. Neuroprotective effects of different modalities of acupuncture on traumatic spinal cord injury in rats. Journal of Evidence-Based Complementary \& Alternative Medicine. 2014;2014:431580.

40. Ma R, Liu X, Clark J, Williams GM, Doi SA. The Impact of Acupuncture on Neurological Recovery in 
Spinal Cord Injury: A Systematic Review and Meta-Analysis. Journal of Neurotrauma. 2015;32(24):19431957. DOI: $10.1089 /$ neu.2014.3866

41. Hirschvogel K, Jurina K, Steinberg TA, Matiasek LA, Matiasek K, Beltrán E, et al. Clinical course of acute canine polyradiculoneuritis following treatment with human IV immunoglobulin. Journal of the American Animal Hospital Association. 2012;48(5):299-309.

42. Youko E, Joaquim JGF, Luna SPL, Gama E.D. Treatment of Acute Polyradiculoneuritis by Acupuncture. In: Proceedings of the $30^{\text {th }}$ Annual International Congress on Veterinary Acupuncture, 2004, Sep 8-11; Oostende, Belgium. Red Hook: Curran \& Associates; 2004. p. 337-344.

43. Joaquim JGF, Luna SPL, Torelli S, Angeli AL, Gama ED. Study of 43 dogs with neurological disease: a western and eastern view of the neurological pattern of diseases. In: Proceedings of the $29^{\text {th }}$ Annual International Congress on Veterinary Acupuncture; 2003 Aug 20-23; Santos, SP, Brazil. Red Hook: Curran \& Associates, 2003. p.289-297.

44. Steiss JE. Canine rehabilitation. In: Steiss JE, Braund KG, ed. Clinical neurology in small animals: localization, diagnosis and treatment. New York: International Veterinary Information Service; 2002. p. 145157.

45. Johnston SA. Osteoarthritis. Joint anatomy, physiology, and pathobiology. Veterinary Clinics of North America: Small Animal Practice. 1997;27(4):699-723.

46. Millis DL, Tichenor M, Hecht S. Prevalence of osteoarthritis in dogs undergoing routine dental prophylaxis. In: Proceedings of the $39^{\text {th }}$ World Small Animal Veterinary Association Meeting; 2014 Sep; Cape Town, South Africa.

47. Joaquim JGF. Uso da acupuntura nas síndromes articulares: primeira ou última opção? Acta Science Veterinary. 2007;35(2):277-278.

48. Schoen AM. Acupuncture for musculoskeletal disorders. Problems in Veterinary Medicine. 1992;4(1):8897.

49. Wong Lit Wan D, Wang Y, Xue CC, Wang LP, Liang FR, Zheng Z. Local and distant acupuncture points stimulation for chronic musculoskeletal pain: A systematic review on the comparative effects. European Journal of Pain. 2015;19(9):1232-1247. DOI: 10.1002/ejp.671

50. Bao F, Sun H, Wu ZH, Wang DH, Zhang YX. Effect of acupuncture on expression of matrix metalloproteinase and tissue inhibitor in cartilage of rats with knee osteoarthritis. Zhongguo Zhen Jiu. 2011;31(3):241-246.

51. Yurtkuran M, Kocagil T. TENS, electroacupuncture and ice massage: comparison of treatment for osteoarthritis of the knee. American Journal of Acupuncture. 1999;27(3-4):133-140.

52. Langevin HM, Schnyer R, MacPherson H, Davis R, Harris RE, Napadow V, et al.; Executive Board of the Society for Acupuncture Research. Manual and electrical needle stimulation in acupuncture research: pitfalls and challenges of heterogeneity. Journal of Alternative and Complementary Medicine. 2015;21(3):113-128. 